\title{
Stress Enhancement of Craving During Sobriety: A Risk for
}

\section{Relapse}

\author{
George R. Breese, Kathleen Chu, Christopher V. Dayas, Douglas Funk, Darin J. Knapp, \\ George F. Koob, Dzung Anh Lê, Laura E. O'Dell, David H. Overstreet, Amanda J. Roberts, \\ Rajita Sinha, Glenn R. Valdez, and Friedbert Weiss \\ Bowles Center for Alcohol Studies (GRB, DJK, DHO), University of North Carolina School of \\ Medicine, Chapel Hill, North Carolina; Centre for Addiction and Mental Health (DAL, DF), University \\ of Toronto, Toronto, Ontario, Canada; Yale University School of Medicine (RS), New Haven, \\ Connecticut; and The Scripps Research Institute (KC, CVD, GFK, AJR, GRV, FW), La Jolla, \\ California
}

\section{Abstract}

This report of the proceedings of a symposium presented at the 2004 Research Society on Alcoholism Meeting provides evidence linking stress during sobriety to craving that increases the risk for relapse. The initial presentation by Rajita Sinha summarized clinical evidence for the hypothesis that there is an increased sensitivity to stress-induced craving in alcoholics. During early abstinence, alcoholics who were confronted with stressful circumstances showed increased susceptibility for relapse. George Breese presented data demonstrating that stress could substitute for repeated withdrawals from chronic ethanol to induce anxiety-like behavior. This persistent adaptive change induced by multiple withdrawals allowed stress to induce an anxiety-like response that was absent in animals that were not previously exposed to chronic ethanol. Subsequently, Amanda Roberts reviewed evidence that increased drinking induced by stress was dependent on corticotropin-releasing factor (CRF). In addition, rats that were stressed during protracted abstinence exhibited anxiety-like behavior that was also dependent on CRF. Christopher Dayas indicated that stress increases the reinstatement of an alcohol-related cue. Moreover, this effect was enhanced by previous alcohol dependence. These interactive effects between stress and alcohol-related environmental stimuli depended on concurrent activation of endogenous opioid and CRF systems. A.D. Lê covered information that indicated that stress facilitated reinstatement to alcohol responding and summarized the influence of multiple deprivations on this interaction. David Overstreet provided evidence that restraint stress during repeated alcohol deprivations increases voluntary drinking in alcoholpreferring $(\mathrm{P})$ rats that results in withdrawal-induced anxiety that is not observed in the absence of stress. Testing of drugs on the stress-induced voluntary drinking implicated serotonin and CRF involvement in the sensitized response. Collectively, the presentations provided convincing support for an involvement of stress in the cause of relapse and continuing alcohol abuse and suggested novel pharmacological approaches for treating relapse induced by stress.

\section{Keywords}

Alcohol; Stress; Craving; Multiple Withdrawals; Repeated Deprivations; Serotonin; CorticotropinReleasing Factor; Flumazenil; Kindling; Adaptation

\section{Copyright $\odot 2005$ by the Research Society on Alcoholism.}

Reprint requests: George R. Breese, PhD, Center For Alcohol Studies, 3007 Thurston-Bowles Building CB-7178, UNC School of Medicine, Chapel Hill, NC 27599; Fax: 919-966-5679; george_breese@ med.unc.edu.. 
ALCOHOLISM IS A disorder that progresses from "social drinking" to a state of uncontrolled abuse. Research has shown that up to two in three alcoholics resume drinking after engaging in alcohol treatment (Hunt et al., 1971; Miller et al., 1996), indicative that relapse is common to this disorder. On the basis of the tension-reduction hypothesis, investigators assumed that increased alcohol intake relates to reducing stress-induced "tension" or anxiety (Brown et al., 1990, 1995; Cooper et al., 1992; Kalodner et al., 1989; Kushner et al., 1994; Young et al., 1990). In this respect, anxiety during abstinence can be a predictor of end-state drinking in the alcoholic (Kushner et al., 1994, 2000, 2001; Sloan et al., 2003; Willinger et al., 2002). However, it is emphasized that not all alcoholics describe an occurrence of anxiety during abstinence (Li, 2000); some exhibit depression and negative affect (Duka et al., 2002; Liappas et al., 2002). In other research, laboratory-induced negative mood was shown to increase alcohol craving (Litt et al., 1990) and risk for relapse in alcoholics (Cooney et al., 1997).

Early research with social drinkers indicated that laboratory exposure to stress increases alcohol consumption (Higgins and Marlatt, 1975; Marlatt et al., 1975). Stress in the abstinent alcoholic in a laboratory setting induces alcohol craving (Litt et al., 1990; Sinha, 2001), and stress has been identified as one of the key factors that are important in relapse (Brown et al., 1990, 1995; Cooney et al., 1997; Pohorecky, 1991; Sinha, 2001; Weiss and Porrino, 2002). Despite evidence implicating stress in maintaining alcohol abuse, documenting evidence for the means by which stress contributes to the pathogenesis of alcoholism has been meager.

This symposium summarizes clinical and preclinical work that documents that stress influences the pharmacology of alcohol and contributes to the characteristics of alcoholism. Clinical evidence provided demonstrates that adaptive mechanisms persist in the alcoholic during abstinence to support the appearance of negative affect and craving. One group of basic studies presents evidence that stress shares in the kindling process that is responsible for worsening withdrawal symptoms that accompany repeated exposures from chronic alcohol. Other preclinical findings demonstrate that stress can facilitate drinking and motivation to drink. Specific neurotransmitters involved in the consequences of stress on various influences related to withdrawal symptoms, alcohol drinking, and motivation to drink are included in this summary.

\section{STRESS INCREASES ALCOHOL CRAVING AND THE RISK FOR RELAPSE}

\section{Rajita Sinha}

Data from a human laboratory model of stress-induced alcohol/drug craving provide evidence for stress-induced drug craving and an association of this response to alcohol relapse. This focus of research elucidated the mechanism underlying the association between stress and drug relapse. Alcohol use has been conceptualized as a stressor that when used chronically results in allostasis and neuroadaptation (Koob and Le Moal, 1997; McEwen, 2000). In humans, previous research showed that chronic alcohol abuse is associated with significant neuroadaptation in brain stress circuits and dysregulation of hypothalamic-pituitary-adrenal (HPA) axis responses in alcoholics (Adinoff et al., 1990, 1991; Sinha, 2001). Protracted withdrawal and early abstinence from chronic alcohol abuse is marked by stress-related symptoms such as sleep difficulties, anxiety, irritability, depressive symptoms, and difficulties in concentration. A hallmark of the protracted withdrawal and abstinence phase has previously been hypothesized as an increased sensitivity to stress and stress-induced craving in drugdependent individuals (Sinha, 2001). This enhanced sensitivity places an alcoholic who is in early recovery at increased susceptibility for craving and a likelihood of relapse when exposed to stressful situations in the environment.

For testing this hypothesis, drug/alcohol craving and stress reactivity were examined in cocaine abusers and alcoholics. Participants were exposed to personal experiences of stress, nonstress 
drug/alcohol cues, and neutral relaxing situations via guided imagery and recall. In a brief 5min exposure in a laboratory setting, participants imagined these situations while scripts with stimulus and response information on the respective events were described to them via audiotape. Initial findings indicated that brief exposure to stress imagery induced drug craving and increased multiple negative emotions of fear, sadness, and anger in cocaine-dependent individuals and in cocaine alcoholics (Sinha et al., 1999). In a second study, we compared stress imagery with nonstress drug cue imagery and neutral-relaxing imagery and reported that significant increases in heart rate, salivary cortisol levels, and subjective anxiety were found to accompany increases in drug/alcohol craving with exposure to stress and to nonstress drug cues as compared with neutral-relaxing cues (Sinha et al., 2000).

In a more extensive inpatient study design, an evaluation was made on the subjective and physiological effects of stress, nonstress drug/alcohol cue, and neutral-relaxing cue exposure in recently abstinent, treatment-seeking cocaine-dependent individuals, half of whom were also dependent on alcohol. The findings indicated that recall/imagery of stress and of drug/ alcohol cue situations in contrast to neutral-relaxing situations, once again, significantly increased alcohol craving (see Fig. 1). Furthermore, these states were accompanied by increased physiological arousal as measured by increases in heart rate, blood pressure, ACTH, prolactin, and cortisol as well as plasma norepinephrine and epinephrine (Sinha et al., 2003).

Subsequently, it was examined whether there was an association between stress-induced alcohol craving in the laboratory and return to drinking after inpatient drug treatment. Findings indicated that stress-induced alcohol craving in this group of participants was significantly associated with number of days of alcohol used $\left(R^{2}=0.20, r=0.45, p<0.001\right)$ and total number of drinks consumed $\left(R^{2}=0.30, r=0.55, p<0.0001\right)$ in the 90-day follow-up period after completion of inpatient drug treatment (see data in Fig. 2). These data suggest that an increased level of stress-induced alcohol craving is associated with alcohol relapse as measured by alcohol intake and number of days of drinking after treatment. The association between other biological stress response markers and alcohol relapse is currently being investigated.

These findings provide initial evidence that stress exposure in abstinent alcoholic individuals increases both alcohol craving and susceptibility to abusing alcohol after treatment completion. Such data support the notion that attenuating stress-induced alcohol craving through pharmacological or psychosocial interventions could be a relevant target in the development of new treatments for alcohol dependence. The studies described here also provide a validated human laboratory method for induction of stress-related alcohol craving that may be used for testing new and existing pharmacological agents in the treatment of alcohol dependence. For example, there is some evidence that serotoninergic reuptake inhibitors attenuate alcoholdrinking behavior and alcohol craving in clinical studies (Johnson et al., 2002; Pettinati et al., 2000), but the specific mechanisms by which they are of benefit in decreasing alcohol consumption are not fully understood. Preclinical research indicates that serotoninergic agents attenuate stress-induced alcohol reinstatement, presumably via regulation of limbic-HPA axis circuits during stress (Lê and Shaham, 2002). Future research that assesses pharmacological agents for their effects on stress-induced alcohol craving and arousal responses will likely increase our understanding of the mechanisms by which stress increases risk for alcohol relapse, which in turn could significantly enhance development of new treatments for alcohol relapse prevention. 


\section{STRESS-INDUCED ANXIETY-LIKE BEHAVIOR DURING ABSTINENCE FROM PREVIOUS ALCOHOL EXPOSURE}

\section{George R. Breese, Darin J. Knapp, and David H. Overstreet}

One view of the process of developing alcohol abuse is the "allostasis model of alcoholism" (see Koob, 2003; Koob and Le Moal, 2001; Roberts et al., 2000a)—a process believed to "kindle" neural processes that are responsible for worsening withdrawal symptoms. The concept of kindling brain circuits to increase susceptibility of seizure activity (Ballenger and Post, 1978; McCown and Breese, 1990) served as an impetus to evaluate the possibility that withdrawal symptoms that are unrelated to seizure kindling could be worsened by repeated withdrawals from chronic alcohol. In support of this concept, Overstreet et al. (2002) found that repeated withdrawals from chronic alcohol exposure increased withdrawal-induced anxiety-like behavior ("anxiety"). Because continuous alcohol presence did not induce this change, the cycling was essential for the adaptive process that is responsible for the sensitized behavior during withdrawal. Factors such as level of alcohol intake and locomotor activity could not explain this increase in anxiety-like behavior. Furthermore, the adaptation by the repeated withdrawals persisted for up to 32 days as demonstrated by examining anxiety-like behavior after withdrawal from a subsequent short exposure to alcohol diet (Overstreet et al., 2002). Thus, it was concluded that this sensitization of anxiety-like behavior induced by repeated withdrawals is the result of a "kindling-like" phenomenon, a finding consistent with repetitive abuse of alcohol increasing allostatic load (Koob, 2003; Koob et al., 2004). This adaptation is presumed to contribute to the worsening of withdrawal symptoms, which enhance the probability of relapse and continued alcohol abuse.

Because of implications that stress induces adaptive change (Lazarus and Folkman, 1984; Sapolsky, 2003), the perspective of whether repeated stresses relate to the adaptive consequence of multiple withdrawals to induce anxiety-like behavior was examined (Breese et al., 2004a). For examining this possibility, two restraint stresses were applied at weekly intervals (i.e., to substitute for repeated withdrawals) followed by withdrawal from a single 5day exposure to an alcohol-containing diet. Whereas withdrawal from the single 5-day alcohol diet exposure alone did not affect anxiety-like behavior, the previous repeated restraint stress experience reduced social interaction during the future single withdrawal (Fig. 3) (Breese et al., 2004a). Two weekly administrations of corticosterone instead of stress did not decrease social interaction upon withdrawal from the 5-day exposure to chronic alcohol (Breese et al., 2004a), a result indicative that peripheral release of corticosterone is not responsible for the stress sensitization of withdrawal-induced "anxiety." Stress in the absence of alcohol exposure did not induce an anxiety-like response. Consistent with stress causing a persistent adaptive change, re-exposure of rats to 5 days of alcohol diet 16 days after being subjected to the stress/ withdrawal protocol significantly enhanced withdrawal-induced anxiety (Breese et al., 2004a).

Given that stress substitutes for repeated withdrawals to sensitize anxiety-like behavior, the possibility existed that adaptation to previous alcohol exposures would allow a subsequent stress to induce an anxiety-like response. In this circumstance, restraint stress that was applied 3 days after a final withdrawal from repeated withdrawals reduced social interaction (see Breese et al., 2004b,c). Animals that were exposed to the multiple-withdrawal protocol but not stressed exhibited no anxiety-associated behavior 3 days after the final withdrawal. These data documenting stress-induced anxiety-like behavior after repeated withdrawals strengthen the view that stress emulates the adaptive change associated with repeated withdrawals (see Breese et al., 2004a,c). Social interaction after stress in the control liquid diet-exposed rats was comparable to that seen in nonstressed rats on control diet. These data emphasize that adaptation related to previous alcohol exposure(s) is a necessity for stress to produce an anxiety- 
like response. Therefore, "stress" in an abstinent alcoholic may be perceived as a "withdrawallike syndrome" capable of producing anxiety-associated symptoms-a view consistent with the reported negative affect and anxiety observed in alcoholics during abstinence (Begleiter and Porjesz, 1979; Roelofs, 1985).

Drug studies have implicated specific neurotransmitter systems in the adaptive changes induced by repeated withdrawals and stress. A 5- $\mathrm{HT}_{1 \mathrm{~A}}$-receptor agonist, corticotropinreleasing factor (CRF) receptor antagonists, and flumazenil have been found to block the anxiety-like behavior induced by repeated withdrawals (Knapp et al., 2004a,b; Overstreet et al., 2003b, 2004). These same drugs block the anxiety-associated response induced by the stress/withdrawal protocol (Breese et al., 2004a). Because the drugs were administered during the first two withdrawals or stress sessions and not during the final withdrawal from chronic alcohol, critical evidence is afforded that repeated withdrawals and the stresses induce adaptation that accumulates from one cycle to the next to sensitize withdrawal symptoms.

In summary, the cumulative adaptive changes from excessive alcohol drinking can interact with stress to increase the severity of withdrawal symptoms. This process in the alcoholic is presumed to contribute to loss of control to limit alcohol consumed with renewed drinking (relapse). The adaptation to previous alcohol exposure can also allow stress to induce negative affect and anxiety during abstinence. The presence of anxiety-like behavior during abstinence from repeated alcohol exposures in the alcoholic is proposed to relate to stressful cues in the environment (Sinha, 2001) (see previous section). The withdrawal-like symptoms to stress during abstinence in the alcoholic would contribute to craving and the likelihood of continued alcohol abuse (see Cooney et al., 1997; Sinha, 2001; Sinha et al., 1999; Sloan et al., 2003; Willinger et al., 2002). Therefore, it is proposed that the progressive accumulation of adaptation interacting with stress contributes to the pathogenesis of alcoholism. This view is consistent with the "kindling"/stress hypothesis of alcoholism (see Breese et al., 2004c).

\section{ALCOHOL DRINKING AND ANXIETY-LIKE BEHAVIOR DURING ABSTINENCE: ROLE OF CRF}

\section{Amanda J. Roberts, Glenn R. Valdez, Laura E. O'Dell, Kathleen Chu, and George F. Koob}

Animal models of alcohol withdrawal and abstinence states associated with increased stress axis activity and increased anxiety states that are relevant to alcoholism have been developed. It has been speculated that this state of "stress" contributes to alcohol relapse. Affective signs of withdrawal in humans include increased anxiety, depressed mood, and increased sensitivity to stressors (Parsons et al., 1990), and these symptoms have been positively correlated with relapse (Cloninger, 1987; De Soto et al., 1989; Hershon, 1977; Miller and Harris, 2000; Mossberg et al., 1985). In animals, alcohol withdrawal has been associated with increased anxiety-like behavior and/or enhanced responsiveness to stressful stimuli (Baldwin et al., 1991; Hölter et al., 1998; Möller et al., 1997; Rasmussen et al., 2001; Rassnick et al., 1993). Recent research demonstrated that the CRF system modulates the contribution of anxiety states to excessive alcohol intake in animal models (Baldwin et al., 1991; Ehlers and Chaplin, 1987; Merlo-Pich et al., 1995; Rassnick et al., 1993; Richter and Weiss, 1999; Timpl et al., 1998). If anxiety-like behavior is critical in mediating alcohol drinking after withdrawal and CRF is important in this withdrawal-induced anxiety, then it should follow that CRF is important in alcohol drinking in dependent individuals. A series of experiments was conducted in rats and mice to examine this possibility.

A model of alcohol self-administration in dependent rats was developed several years ago (Roberts et al., 1996, 2000a,b) and has been refined (O'Dell et al., 2004). In this model, rats are trained to press a lever for alcohol and then are made dependent through alcohol vapor 
exposure and finally allowed to press a lever again during the early phases of alcohol withdrawal or after more extended periods of abstinence. Operant responding for alcohol is increased both during the acute withdrawal phase [0-12 hr (Roberts et al., 1996)] and after protracted abstinence [2-8 weeks (Roberts et al., 2000a)]. Anxiety-like behavior, as determined by a decrease in open-arm exploration in the elevated plus maze, also is increased at $2 \mathrm{hr}$ and 4 weeks after alcohol withdrawal (Valdez et al., 2002). These consequences suggest that the increased alcohol self-administration observed in dependent rats may be the result of a heightened stress response.

The effect of intracerebroventricular administration of a CRF receptor antagonist on alcohol self-administration in dependent rats was examined. D-Phe-CRF(1,2-41) significantly decreased alcohol self-administration in dependent rats, both during withdrawal and after protracted abstinence, but had no effect on self-administration in nondependent rats (Valdez et al., 2002). In a separate study, it was shown that D-Phe-CRF(1,2-41) reversed the stressorinduced increase in anxiety-like behavior observed after protracted abstinence (Valdez et al., 2003). Therefore, CRF may have a role in the motivational effects of withdrawal and protracted abstinence associated with increases in alcohol consumption.

Recently, the role of CRF in alcohol self-administration and anxiety-like behavior associated with dependence was explored in mice. In addition to behavioral and neuropharmacological studies, the availability of genetically mutated mice provides an important additional means of mechanistic investigation. The mouse studies performed thus far have extended the rat studies outlined above by focusing on the role of specific CRF receptors. For example, CRF receptor 1 (CRF1) null mutant and wild-type littermate control mice were exposed to either an alcohol-containing liquid diet or a control liquid diet for 26 days. Alcohol was removed, and the mice were tested for anxiety-like behavior in the light/dark transfer test $24 \mathrm{hr}$ into withdrawal and then the alcohol liquid diet was restored. Five days later, the mice were withdrawn and tested again, and a third withdrawal test was performed after another 5 days of liquid diet exposure. Wild-type mice showed a progressive increase in alcohol withdrawalinduced anxiety-like behavior across the three withdrawal tests; however, CRF1 null mutant mice did not show increases in this behavior during any of the three withdrawals. The genotypes had equivalent blood alcohol levels throughout the exposure period. The finding that mice that lack CRF1 receptors do not show increases in alcohol withdrawal-induced increases in anxietylike behavior suggests that this receptor is necessary for the expression of alcohol withdrawalinduced anxiety-like behavior.

A mouse model of excessive alcohol self-administration after dependence induction and periods of protracted abstinence has been developed. C57BL/6J mice were trained to press a lever for alcohol using a saccharin fading procedure (i.e., Roberts et al., 2000b, 2001). Once stable baseline alcohol self-administration was established, half of the mice were exposed to alcohol vapor for $14 \mathrm{hr} /$ day and all mice were tested in 1-hr self-administration sessions 5 days/ week. The timing of self-administration was $8 \mathrm{hr}$ into the 10-hr "vapor off" period. Mice received alcohol vapor for 1 month and then continued to be tested for an additional 3 weeks after withdrawal. There were no differences in alcohol self-administration between control mice and those that were exposed to alcohol vapor during the 1-month vapor exposure phase. There was a tendency for mice that were exposed to alcohol vapor to decrease their alcohol self-administration during the first week after removal from the vapor (i.e., there was no increase in alcohol self-administration during the early withdrawal phase). However, mice that were exposed to alcohol vapor showed increased alcohol self-administration relative to control mice after protracted abstinence (particularly the third week after withdrawal). Most of the mice $(75 \%)$ that experienced protracted abstinence responded for more than $1 \mathrm{~g} / \mathrm{kg}$ of alcohol, a finding that suggests induction of alcohol dependence in the mice under these conditions. 
Using this model, the role of CRF1 in mediating the increased operant self-administration observed after protracted abstinence was explored. C57BL/6J mice were trained to press a lever for $10 \%$ alcohol, and then half were made dependent in alcohol vapor chambers as described above. Mice were allowed a 2-week abstinence period and then received either vehicle or the nonpeptide CRF1 antagonist antalarmin intraperitoneally. Antalarmin significantly decreased alcohol self-administration in mice that underwent protracted abstinence, whereas there was no effect on alcohol self-administration in control mice. This outcome is consistent with the results from the CRF1 null mutant mice mentioned above in supporting a role for the CRF1 in mediating the motivational effects of withdrawal and protracted abstinence.

In summary, abstinence is associated with increased alcohol self-administration and increased anxiety-like behavior in both rats and mice. The behavioral and physiological changes that contribute to relapse extend beyond the period generally associated with physical withdrawal signs. An important component of dependence is emphasized to be motivation to drink alcohol. CRF receptor antagonism blocked behavioral effects in rats and the excessive alcohol selfadministration observed in mice after protracted abstinence. Finally, CRF1 null mutant mice did not show the increase in anxiety-like behavior associated with abstinence.

Taken together, these data suggest that the increased alcohol self-administration in dependent animals is associated with an increased behavioral responsiveness to stress and that this link is mediated by CRF. More specific, CRF1 receptors seem to play an important role in the contribution of anxiety states to excessive alcohol intake and dependence.

\section{STRESS AND SUSCEPTIBILITY TO ALCOHOL RELAPSE IN RATS}

\section{Christopher V. Dayas and Friedbert Weiss}

Stress is thought to represent an important risk factor for relapse in abstinent alcoholics. Consistent with a role of stress in motivating the resumption of drinking, footshock-a stimulus commonly used to model acute stress in the animal literature - effectively provokes reinstatement of extinguished alcohol-seeking behavior in rodent models of relapse. Evidence is emerging that drug-seeking responses elicited by stress are subject to modification by other risk factors for relapse, such as the presence of alcohol-related environmental stimuli, and by neuroadaptive dysregulation of brain stress-regulatory systems that develop as a result of chronic alcohol intoxication.

An initial set of experiments (Liu and Weiss, 2002) revealed that when presentation of a previously alcohol-paired cue is preceded by stress, the response-reinstating actions of the alcohol cue are greatly increased; moreover, this effect is further enhanced in previously alcohol-dependent rats. The interactive effects between stress and alcohol-related environmental stimuli were found to be dependent on concurrent activation of endogenous opioid and CRF systems. Specifically, the effects of the alcohol cue were selectively sensitive to reversal by the opiate antagonist naltrexone, whereas the effects of footshock stress were selectively sensitive to reversal by the CRF antagonist D-Phe-CRF(12-41). Both of these agents, however, only partially reversed the enhanced drug-seeking response produced by combined exposure to stress and the alcohol cue. Full reversal of alcohol-seeking behavior was observed only after co-administration of D-Phe-CRF(12-41) and naltrexone. These findings show that stress and drug-related environmental stimuli can interact to augment relapse risk. In addition, these observations suggest that neuroadaptive disturbances in brain reward and stress systems may augment the susceptibility to cue- or stress-induced alcohol-seeking behavior.

Recent studies suggest that stress-induced reinstatement generally occurs independent of activation of the principal endocrine response to stress (Lê et al., 2000), corticosterone release, 
which is triggered by activation of hypothalamic, paraventricular nucleus (PVN), medial parvocellular CRF cells that sit at the apex of the HPA axis. However, Goeders and Clampitt (2002) demonstrated that environmental cues that were previously paired with drug availability acutely activate the HPA axis, which result in elevated plasma levels of corticosterone. Indeed, blockade of corticosterone release by peripheral injections of ketoconazole, a corticosterone synthesis inhibitor, suppresses cue-induced reinstatement of cocaine seeking (Goeders and Clampitt, 2002). For investigating a potential role for HPA axis activation in cue-induced reinstatement of alcohol seeking, animals were given bilateral injections of the highly selective neuronal nitric oxide synthase inhibitor (nNOSi) N-propyl-L-arginine $(5 \mathrm{nmol} / \mathrm{injection})$ into the PVN 30 min before reinstatement testing. Compared with vehicle-treated animals, injections of the nNOSi significantly suppressed reinstatement evoked by an alcoholassociated stimulus. These data do not, as yet, shed light on the mechanism by which an nNOSi acts to block cue-induced alcohol seeking. However, given that inhibition of NO production in the PVN is known to suppress HPA axis responses to stress (Kim and Rivier, 2000), it was speculated that PVN-directed nNOSi injections might suppress HPA axis activity evoked by presentation of the alcohol-associated stimulus (Goeders and Clampitt, 2002). Further work, including additional doses of $\mathrm{N}$-propyl-L-arginine and plasma corticosterone measurements, are required to verify this conclusion. It is interesting that these data are also consistent with previous findings that peripheral injection of a nonspecific NOSi N (G)-nitro-L-arginine methyl ester blocks cue-induced reinstatement of alcohol-seeking but not alcohol self-administration (Liu and Weiss, 2004).

As highlighted above, co-administration of D-Phe CRF and naltrexone completely reversed the interactive effects on alcohol seeking by combined exposure to stress and alcoholassociated stimuli (Liu and Weiss, 2002). These data suggest that pharmacotherapeutic strategies for relapse prevention would ideally target mechanisms that regulate both stress- and cue-induced alcohol seeking. Novel data on the effects of the opioid-like peptide nociceptin/ orphanin FQ (N/OFQ) have been interesting in this regard. N/OFQ is a 17-amino acid peptide that shows sequence homology with classical opiate peptides that has little or no affinity for the classical opioid receptors. N/OFQ has been shown to have "antiopioid" and "antistress" effects. For example, N/OFQ can prevent morphine-induced analgesia and block morphineinduced conditioned place preference (Ciccocioppo et al., 2000; King et al., 1998). With respect to its "antistress" effects, nociceptin has been demonstrated to have anxiolytic actions and can reverse the anorexic effects of CRF, restraint, or footshock stress (Ciccocioppo et al., 2001, 2003; Jenck et al., 2000; Martin-Fardon et al., 2000). Our recent findings that N/OFQ effectively attenuates the reinstatement of alcohol-seeking in response to both stress- and alcohol-associated stimuli suggests a therapeutic potential for nociceptin receptor ligands in the treatment of alcohol dependence and relapse (Ciccocioppo et al., 2001, 2003; MartinFardon et al., 2000).

Data from a final set of experiments suggest that chronic psychological stress (acute footshock, $10 \mathrm{~min} /$ day 7 days) but not physiological stress (once-daily injections of lipopolysaccharide for 7 days) suppresses the alcohol-deprivation effect (ADE) in animals with a history of alcohol dependence (Dayas et al., 2004). The rebound increase in alcohol consumption observed in response to abstinence from alcohol, defined as the ADE, is also thought to be a rodent model of relapse. It is interesting that only nonstressed animals and those that were treated with lipopolysaccharide exhibited an ADE and increased consumption. Whether an increase in intensity, duration, or both is required to produce footshock enhancement of alcohol consumption during abstinence warrants further investigation. The discrepancies in the alcohol consumption literature, particularly with respect to footshock that reliably reinstates alcoholseeking in animal models, emphasizes the importance of continued investigation and development of appropriate models of alcohol consumption in laboratory animals to mimic clinical findings. 
In summary, evidence has been provided that alcohol-associated cues and stress can exacerbate relapse risk especially in animals with a history of dependence. Moreover, a role for the HPA axis may exist in triggering cue-induced alcohol seeking. Novel pharmacological treatments that target the N/OFQ system may have therapeutic potential in suppressing alcohol relapse associated with stress and alcohol cue exposure. Finally, the need is highlighted for the development of effective and valid models of stress-induced alcohol consumption.

\section{FEATURES OF STRESS AND RELAPSE TO ALCOHOL IN EXPERIMENTAL ANIMALS}

\section{Anh D. Lê and Douglas Funk}

Exposure to stressful life events is associated with increased relapse to alcohol use in humans. Several models have been developed to study relapse to alcohol in laboratory animals. Of these, the reinstatement procedure and ADE are the two most commonly used (Lê and Shaham, 2002). For studying the effects of stress on alcohol seeking, the reinstatement procedure was used. In this model, animals are trained to press a lever for alcohol, the operant response is extinguished, and the effect of exposure to acutely administered stressors on the reinstatement of the lever-pressing response is examined. Using this procedure, exposure to intermittent footshock stress can reinstate extinguished responding for alcohol.

Not all stressors, however, reinstate extinguished responding for alcohol. For example, exposure to various durations of restraint stress ranging from 15 to $60 \mathrm{~min}$ or to various doses of the anxiogenic benzodiazepine inverse agonist FG7142 did not reinstate responding for alcohol. However, exposure to an odor cue previously associated with social defeat stress, or to yohimbine, an $\alpha-2$ adrenergic receptor antagonist, can significantly reinstate alcohol seeking. The reinstatement of alcohol seeking induced by exposure to odor cues previously paired with social defeat is characterized by large individual variation, whereas the effects of yohimbine are more robust and occurred in most of the subjects. A number of potential mechanisms might account for the differential effects of various stressors on the reinstatement of alcohol seeking. The effects of footshock stress on the reinstatement of heroin or cocaine seeking were context dependent, with reinstatement of drug seeking occurring only when footshock stress was delivered in the operant chambers where the animals were previously trained to self-administer the drug but not when footshock stress was administered outside the operant conditioning chambers (see Shalev et al., 2000, for further discussion). It therefore is possible that the failure of restraint stress to reinstate alcohol seeking might be because the stressor was applied outside the environment previously associated with alcohol self-administration.

Another possibility is that the various stressors might have differential effects on CRF in brain nuclei involved in stress-induced relapse. In this respect, previous work found that CRF plays a primary role in stress-induced reinstatement of alcohol seeking as intraventricular injections of CRF can reinstate alcohol seeking, whereas pretreatment with CRF receptor antagonists blocks reinstatement of alcohol seeking induced by exposure to footshock stress (Lê et al., 2000). In support of this, preliminary data (Funk et al., unpublished data) with the benzodiazepine inverse agonist FG-7142 and yohimbine indicate that acute administration of these drugs produces differential effects on the expression of CRF mRNA in the bed nucleus of stria terminalis.

Another widely used model of relapse is based on the observation that alcohol-experienced animals consumed more alcohol after a period of deprivation. This increase in alcohol consumption has come to be known as the ADE. The ADE has a number of features that recommend it as a model of relapse in humans (Heyser et al., 1997; Lê and Shaham 2002; Li, 2000). Exposure to footshock stress or social defeat during the deprivation phase facilitates the 
development of the ADE (Funk et al., 2004). Similar to the effect observed in the reinstatement procedure, exposure to intermittent footshock stress has a greater influence on the ADE than does exposure to social defeat stress. Whether other stressors might facilitate the development of ADE still remains to be examined (see next section). That these stressors significantly affect alcohol seeking in two different animal models of relapse further confirms the importance of stress in relapse to alcohol.

In our previous work, inhibition of the 5-hydroxytryptamine (5-HT) projections derived from the median raphe but not the dorsal raphe by the local infusion of 8-OH-DPAT, a 5-HT $1 \mathrm{~A}$ receptor agonist, reinstated alcohol seeking (Lê et al., 2002). Because impaired functioning of brain 5-HT is associated with deficits in inhibitory control or impulsivity (Fletcher, 1993; Poulos et al., 1996), it is possible that an impairment of response inhibition might be part of the mechanisms by which stress mediates relapse to alcohol.

Recently, the impact of stress in the motivational effect of alcohol using the conditioned place preference paradigm was examined (Funk et al., 2004). Rats developed place aversion to a distinctive compartment in which they previously received four pairings of alcohol $(1.0 \mathrm{~g} / \mathrm{kg})$, compared with the compartment in which they previously received saline injections. Exposure to footshock or social defeat stress before alcohol treatment, however, completely abolished the place aversion induced by alcohol (Funk et al., 2004). These results raise the possibility that stress might modify the rewarding effect of alcohol by diminishing its aversive effects.

In summary, exposure to stress can reliably promote relapse to alcohol as assessed with two different animal models of relapse. These effects of stress on relapse to alcohol and alcohol dependence, however, are complex and likely involve multiple mechanisms or processes.

\section{RESTRAINT STRESS, INCREASED ALCOHOL DRINKING, ALCOHOL WITHDRAWAL, AND ANXIETY}

\section{David H. Overstreet, Darin J. Knapp, and George R. Breese}

Stress has been implicated in precipitating relapse in alcoholics (Sinha, 2001), but the relationship between stress and alcohol intake in both animals and humans has been and remains controversial. A recent paper showed that chronic (10 days) unpredictable restraint stress reduced voluntary alcohol drinking in $\mathrm{P}$ rats or the high alcohol drinking rats during the application of stress; however, drinking increased in the $\mathrm{P}$ rats after termination of stress (Chester et al., 2004). Stress has also been implicated in the induction of anxiety-like behavior (Breese et al., 2004a,b,c; Valdez et al., 2002). By using a modified repeated withdrawal protocol in P rats (see Overstreet et al., 2002, 2003b, 2004), it was possible to explore the relationship between these variables. Another well-characterized phenomenon in the $\mathrm{P}$ rat is the ADE, whereby rats exhibit increased drinking of and preference for alcohol after a period of deprivation (e.g., McKinzie et al., 1998; Rodd-Henricks et al., 2000a,b). Some have suggested that repeated deprivation/withdrawal periods can induce anxiety-like behavior (Hölter et al., 1998; Spanagel and Hölter, 1999), but such investigations had not been performed in the $\mathrm{P}$ rat.

The increase in withdrawal-induced anxiety behavior in Sprague-Dawley rats was blocked or reduced by treatments with specific pharmacological actions during the early withdrawal periods (Breese et al., 2004b; Knapp et al., 2004; Overstreet et al., 2003a,b, 2004). Effective treatments included flumazenil, a benzodiazepine receptor antagonist; buspirone, a 5-HT $1 \mathrm{~A}$ receptor partial agonist; and CP154,526, a CRF receptor antagonist. These compounds were examined, therefore, in P rats that were subjected to multiple cycles of alcohol exposure and withdrawal/deprivation and stress. The findings suggest a close but imperfect link between the 
elevated voluntary drinking induced by stress and the withdrawal-induced anxiety-like behavior.

The $\mathrm{P}$ rats were selected from the breeding colonies maintained in the University of North Carolina Bowles Center for Alcohol Studies at an initial age of 50 days. They were divided into four groups: (1) access to water only throughout the study; (2) adapted to drink alcohol voluntarily and then provided with continuous, simultaneous access to water and $10 \%$ alcohol solution; (3) adapted to drink alcohol voluntarily and then subjected to three cycles of 5 days' exposure to a choice between tap water and $10 \%$ alcohol; two 2-day periods of deprivation/ withdrawal were interposed after the first and second cycles; or (4) adapted to drink alcohol voluntarily and then subjected to the same conditions as 3, with an additional variable. At $4 \mathrm{hr}$ into the first and second withdrawals, these rats were subjected to restraint stress for $1 \mathrm{hr}$. Group 4 rats were also divided into multiple subgroups on the basis of drug treatments that they received $30 \mathrm{~min}$ before the application of restraint stress during the first and second deprivation/ withdrawal periods.

After the animals completed their three cycles of 5 days of access to water or $10 \%$ alcohol (or 15 consecutive days for the continuous group), they were withdrawn from alcohol and tested for anxiety-like behavior in the social interaction test (see File and Seth, 2003). The deprivedonly group and the restrained, deprived group drank significantly more alcohol on the first day after alcohol was returned on both the second and third cycles. However, whereas the alcohol intake of the deprived-only group decreased on subsequent days, the restrained, deprived group continued to drink higher amounts of alcohol. Furthermore, when withdrawn from alcohol, the restrained, deprived group exhibited less time in social interaction (i.e., increased anxiety-like behavior). Thus, restraint stress and alcohol deprivation/withdrawal interact to induce both higher drinking and increased anxiety-like behavior.

Flumazenil, CRF1-receptor antagonists, and buspirone all reduced alcohol drinking and anxiety-like behavior induced by restraint stress and repeated withdrawals. Thus, these compounds have similar effects in $\mathrm{P}$ rats as they do in counteracting anxiety-like behavior in Sprague-Dawley rats that are maintained on forced alcohol diets (Breese et al., 2004b; Knapp et al., 2004b; Overstreet et al., 2003b, 2004). These initial pharmacological findings suggest that the elevated drinking and the anxiety-like behavior may be closely linked and are subserved by the same underlying neural mechanisms.

However, further study with additional compounds has separated the two behaviors. Naloxone, an opiate receptor antagonist; haloperidol, $\mathrm{a} \mathrm{D}_{2}$-dopamine receptor antagonist; and SB-242084, a $5-\mathrm{HT}_{2 \mathrm{C}}$ receptor antagonist, all reduced the elevated alcohol drinking induced by restraint stress but did not counteract the increased anxiety-like behavior. The negative result with SB-242084 was consistent with its inability to prevent the sensitized anxiety-like behavior seen in stressed rats that were exposed to alcohol diet (Breese et al., 2004a). Thus, opiate, dopaminergic, and 5- $\mathrm{HT}_{2 \mathrm{C}}$ mechanisms seemed to be differentially involved in the two behaviors.

It is important to appreciate that the present design called for the stress and drug treatments to be given $\sim 2$ to 6 days before the recording of alcohol-drinking behavior and 7 days before the assessment of withdrawal-induced anxiety-like behavior. Therefore, any consequences on the two behaviors are most likely the result of their influence on an adaptive process.

\section{CONCLUSIONS}

This symposium provides convincing evidence that excessive use of alcohol leads to persistent adaptive change that interacts with stress. In this respect, environmental cues during abstinence in the alcoholic can be stressful, which may increase symptoms of negative affect and anxiety 
-circumstances that result in craving, loss of control to limit alcohol consumed with relapse, and the likelihood of continued alcohol abuse. Basic studies have provided a solid basis on which future investigations can provide the means by which the negative aspects of stress interacting with the progressive pathogenesis associated with the alcohol abuse can be addressed.

\section{Acknowledgments}

This research was supported by grants from the National Institute on Alcohol Abuse and Alcoholism.

\section{REFERENCES}

Adinoff B, Martin PR, Bone GH, Eckardt MJ, Roehrich L, George DT, Moss HB, Eskay R, Linnoila M, Gold PW. Hypothalamic-pituitary-adrenal axis functioning and cerebrospinal fluid corticotropin releasing hormone and corticotropin levels in alcoholics after recent and long-term abstinence. Arch Gen Psychiatry 1990;47:325-330. [PubMed: 2157379]

Adinoff B, Risher-Flowers D, DeJong J, Ravitz B, Bone GH, Nutt DJ, Roehrich L, Martin PR, Linnoila M. Disturbances of hypothalamic-pituitary-adrenal axis functioning during withdrawal in six men. Am J Psychiatry 1991;148:1023-1025. [PubMed: 1853950]

Baldwin HA, Rassnick S, Rivier J, Koob GF, Britton KT. CRF antagonist reverses the "anxiogenic" response to ethanol withdrawal in the rat. Psychopharmacology 1991;103:227-232. [PubMed: 2027923]

Ballenger JC, Post RM. Kindling as a model for alcohol withdrawal syndromes. Br J Psychiatry 1978;133:1-14. [PubMed: 352467]

Begleiter H, Porjesz B. Persistence of a "subacute withdrawal syndrome" following chronic ethanol intake. Drug Alcohol Depend 1979;4:353-357. [PubMed: 118857]

Breese GR, Knapp DJ, Overstreet DH. Stress sensitization of the ethanol withdrawal-induced deficit in social interaction: inhibition by CRF-1 and benzodiazepine receptor antagonists and a $5-\mathrm{HT}_{1 \mathrm{~A}}$ agonist. Neuropsychopharmacology 2004a;29:470-482. [PubMed: 12955093]

Breese GR, Knapp DJ, Overstreet DH. Stress-induced anxiety-like behavior during abstinence from previous chronic ethanol exposure. Alcohol Clin Exp Res 2004b;28:191A.

Breese GR, Overstreet DH, Knapp DJ. Conceptual framework for the etiology of alcoholism: a "kindling"/stress hypothesis. Psychopharmacology. 2004c 2004 Oct 23; [Epub ahead of print].

Brown SA, Vik PW, McQuaid JR, Patterson TL, Irwin MR, Grant I. Severity of psychosocial stress and outcome of alcoholism treatment. J Abnorm Psychol 1990;99:344-348. [PubMed: 2266207]

Brown SA, Vik PW, Patterson TL, Grant I, Schuckit MA. Stress, vulnerability and adult alcohol relapse. J Stud Alcohol 1995;56:538-545. [PubMed: 7475034]

Chester JA, Blose AM, Zweifel M, Froehlich JM. Effects of stress on alcohol consumption in rats selectively bred for high or low alcohol drinking. Alcohol Clin Exp Res 2004;28:385-393. [PubMed: 15084895]

Ciccocioppo R, Angeletti S, Sanna PP, Weiss F, Massi M. Effect of nociceptin/orphanin FQ on the rewarding properties of morphine. Eur J Pharmacol 2000;404:153-159. [PubMed: 10980274]

Ciccocioppo R, Fedeli A, Economidou D, Policani F, Weiss F, Massi M. The bed nucleus is a neuroanatomical substrate for the anorectic effect of corticotropin-releasing factor and for its reversal by nociceptin/orphanin FQ. J Neurosci 2003;23:9445-9451. [PubMed: 14561874]

Ciccocioppo R, Martin-Fardon R, Weiss F, Massi M. Nociceptin/orphanin FQ inhibits stress- and CRFinduced anorexia in rats. Neuroreport 2001;12:1145-1149. [PubMed: 11338181]

Cloninger CR. Neurogenetic adaptive mechanisms in alcoholism. Science 1987;236:410-416. [PubMed: 2882604]

Cooney NL, Litt MD, Morse PA, Bauer LO, Gaupp LJ. Alcohol cue reactivity, negative-mood reactivity, and relapse in treated alcoholic men. J Abnorm Psychol 1997;106:243-250. [PubMed: 9131844]

Cooper ML, Russell M, Skinner JB, Frone MR, Mudar P. Stress and alcohol use: moderating effects of gender, coping, and alcohol expectancies. J Abnorm Psychol 1992;101:139-152. [PubMed: 1537960] 
Dayas CV, Martin-Fardon R, Thorsell A, Weiss F. Chronic footshock, but not a physiological stressor, suppresses the alcohol deprivation effect in dependent rats. Alcohol Alcohol 2004;39:190-196. [PubMed: 15082455]

De Soto CB, O'Donnell WE, De Soto JL. Long-term recovery in alcoholics. Alcohol Clin Exp Res 1989;13:693-697. [PubMed: 2688470]

Duka T, Townshend JM, Collier K, Stephens DN. Kindling of withdrawal: a study of craving and anxiety after multiple detoxifications in alcoholic inpatients. Alcohol Clin Exp Res 2002;26:785-795. [PubMed: 12068246]

Ehlers CL, Chaplin RI. Chronic ethanol exposure potentiates the locomotor activating effects of corticotropin-releasing factor (CRF) in rats. Regul Pept 1987;19:345-353. [PubMed: 3501867]

File SE, Seth P. A review of 25 years of the social interaction test. Eur J Pharmacol 2003;463:35-53. [PubMed: 12600701]

Fletcher PJ. A comparison of the effects of dorsal and median raphe injections of 8-OH-DPAT in three operant tasks measuring response inhibition. Behav Brain Res 1993;54:187-197. [PubMed: 8323715]

Funk D, Vohra S, Le AD. Influence of stressors on the rewarding effects of alcohol in Wistar rats: studies with alcohol deprivation and place conditioning. Psychopharmacology 2004;176:82-87. [PubMed: 15064919]

Goeders NE, Clampitt DM. Potential role for the hypothalamo-pituitary-adrenal axis in the conditioned reinforcer-induced reinstatement of extinguished cocaine seeking in rats. Psychopharmacology 2002;161:222-232. [PubMed: 12021825]

Hershon HI. Alcohol withdrawal symptoms and drinking behavior. J Stud Alcohol 1977;38:953-971. [PubMed: 881849]

Heyser CJ, Schulteis G, Koob GF. Increased ethanol self-administration after a brief period of imposed ethanol deprivation in rats trained in a limited access paradigm. Alcohol Clin Exp Res 1997;21:784791. [PubMed: 9267526]

Higgins RL, Marlatt GA. Fear of interpersonal evaluation as a determinant of alcohol consumption in male social drinkers. J Abnorm Psychol 1975;84:644-651. [PubMed: 1194525]

Hölter SM, Engelmann M, Kirschke C, Liebsch G, Landgraf R, Spanagel R. Long-term ethanol selfadministration with repeated ethanol deprivation episodes changes ethanol drinking pattern and increases anxiety-related behaviour during ethanol deprivation in rats. Behav Pharmacol 1998;9:4148. [PubMed: 9832947]

Hunt WA, Barnett LW, Branch LG. Relapse rates in addiction programs. J Clin Psychol 1971;27:455456. [PubMed: 5115648]

Jenck F, Wichmann J, Dautzenberg FM, Moreau JL, Ouagazzal AM, Martin JR, Lundstrom K, Cesura AM, Poli SM, Roever S, Kolczewski S, Adam G, Kilpatrick G. A synthetic agonist at the orphanin FQ/nociceptin receptor ORL1: anxiolytic profile in the rat. Proc Natl Acad Sci USA 2000;97:49384943. [PubMed: 10758169]

Johnson BA, Roache JD, Ait-Daoud N, Zanca NA, Velazquez M. Ondansetron reduces the craving of biologically predisposed alcoholics. Psychopharmacology 2002;160:408-413. [PubMed: 11919668]

Kalodner CR, Delucia JL, Ursprung AW. An examination of the tension reduction hypothesis: the relationship between anxiety and alcohol in college students. Addict Behav 1989;14:649-654. [PubMed: 2618848]

Kim CK, Rivier CL. Nitric oxide and carbon monoxide have a stimulatory role in the hypothalamicpituitary-adrenal response to physico-emotional stressors in rats. Endocrinology 2000;141:22442253. [PubMed: 10830314]

King M, Chang A, Pasternak GW. Functional blockade of opioid analgesia by orphanin FQ/nociceptin. Biochem Pharmacol 1998;55:1537-1540. [PubMed: 10076548]

Knapp DJ, Angel RA, Overstreet DH, Breese GR. The prophylactic effects of flurnozenil on repeated ethanol withdrawal-induced anxiety are mediated by the amygdala. Alcohol Clin Exp Res 2004a; 28:142A.

Knapp DJ, Overstreet DH, Moy SS, Breese GR. SB242084, flumazenil, and CRA1000 block ethanol withdrawal-induced anxiety. Alcohol 2004b;32:101-111. [PubMed: 15163561] 
Koob GF. Alcoholism: allostasis and beyond. Alcohol Clin Exp Res 2003;27:232-243. [PubMed: 12605072]

Koob GF, Ahmed SH, Boutrel B, Chen SA, Kenny PJ, Markou A, O'Dell LE, Parsons LH, Sanna PP. Neurobiological mechanisms in the transition from drug use to drug dependence. Neurosci Biobehav Rev 2004;27:739-749. [PubMed: 15019424]

Koob GF, Le Moal M. Drug abuse: hedonic homeostatic dysregulation. Science 1997;278:52-58. [PubMed: 9311926]

Koob GF, Le Moal M. Drug addiction, dysregulation of reward, and allostasis. Neuropsychopharmacology 2001;24:97-129. [PubMed: 11120394]

Kushner MG, Abrams K, Borchardt C. The relationship between anxiety disorders and alcohol use disorders: a review of major perspectives and findings. Clin Psychol Rev 2000;20:149-171. [PubMed: 10721495]

Kushner MG, Sher KJ, Wood MD, Wood PK. Anxiety and drinking behavior: moderating effects of tension-reduction alcohol outcome expectancies. Alcohol Clin Exp Res 1994;18:852-860. [PubMed: 7978095]

Kushner MG, Thuras P, Abrams K, Brekke M, Stritar L. Anxiety mediates the association between anxiety sensitivity and coping-related drinking motives in alcoholism treatment patients. Addict Behav 2001;26:869-885. [PubMed: 11768549]

Lazarus, RS.; Folkman, S. Stress, Appraisal and Coping. Springer; New York: 1984.

Lê AD, Harding S, Juzytsch W, Fletcher PJ, Shaham Y. The role of corticotropin-releasing factor in the median raphe nucleus in relapse to alcohol. J Neurosci 2002;22:7844-7849. [PubMed: 12223536]

Lê AD, Harding S, Juzytsch W, Watchus J, Shalev U, Shaham Y. The role of corticotrophin-releasing factor in stress-induced relapse to alcohol-seeking behavior in rats. Psychopharmacology 2000;150:317-324. [PubMed: 10923760]

Lê AD, Shaham Y. Neurobiology of relapse to alcohol in rats. Pharmacol Ther 2002;94:137-156. [PubMed: 12191599]

Li T-K. Clinical perspectives for the study of craving and relapse in animal models. Addiction 2000;95 (Suppl 2):S55-S60. [PubMed: 11002902]

Liappas J, Paparrigopoulos T, Tzavellas E, Christodoulou G. Impact of alcohol detoxification on anxiety and depressive symptoms. Drug Alcohol Depend 2002;68:215-220. [PubMed: 12234651]

Litt MD, Cooney NL, Kadden RM, Gaupp L. Reactivity to alcohol cues and induced mood in alcoholics. Addict Behav 1990;15:137-146. [PubMed: 2343787]

Liu X, Weiss F. Additive effect of stress and drug cues on reinstatement of ethanol seeking: exacerbation by history of dependence and role of concurrent activation of corticotropin-releasing factor and opioid mechanisms. J Neurosci 2002;22:7856-7861. [PubMed: 12223538]

Liu X, Weiss F. Nitric oxide synthesis inhibition attenuates conditioned reinstatement of ethanol-seeking, but not the primary reinforcing effects of ethanol. Alcohol Clin Exp Res 2004;28:1194-1199. [PubMed: 15318118]

Marlatt GA, Kosturn CF, Lang AR. Provocation to anger and opportunity for retaliation as determinants of alcohol consumption in social drinkers. J Abnorm Psychol 1975;84:652-659. [PubMed: 1194526]

Martin-Fardon R, Ciccocioppo R, Massi M, Weiss F. Nociceptin prevents stress-induced ethanol- but not cocaine-seeking behavior in rats. Neuroreport 2000;11:1939-1943. [PubMed: 10884047]

McCown TJ, Breese GR. Multiple withdrawals from chronic ethanol "kindles" inferior collicular seizure activity: evidence for kindling of seizures associated with alcoholism. Alcohol Clin Exp Res 1990;14:394-399. [PubMed: 2378423]

McEwen BS. Allostasis and allostatic load: implications for neuropsychopharmacology. Neuropsychopharmacology 2000;22:108-124. [PubMed: 10649824]

McKinzie DL, Nowak KL, Yorger L, McBride WJ, Murphy JM, Lumeng L, Li T-K. The alcohol deprivation effects in the alcohol-preferring $\mathrm{P}$ rat under free-drinking and operant access conditions. Alcohol Clin Exp Res 1998;22:1170-1176. [PubMed: 9726292]

Merlo-Pich E, Lorang M, Yeganeh M, Rodriguez de Fonseca F, Raber J, Koob GF, Wess F. Increase of extracellular corticotropin-releasing factor-like immunoreactivity levels in the amygdala of awake rats during restraint stress and ethanol withdrawal as measured by microdialysis. J Neurosci 1995;15:5439-5477. [PubMed: 7643193] 
Miller WR, Harris RJ. A simple scale of Gorski's warning signs for relapse. J Stud Alcohol 2000;61:759_ 765. [PubMed: 11022817]

Miller WR, Westerberg VS, Harris RJ, Tonigan JS. What predicts relapse? Prospective testing of antecedent models. Addiction 1996;91:S155-S171. [PubMed: 8997790]

Möller C, Wiklund L, Sommer W, Thorsell A, Heilig M. Decreased experimental anxiety and voluntary ethanol consumption in rats following central but not basolateral amygdala lesions. Brain Res 1997;760:94-101. [PubMed: 9237523]

Mossberg D, Liljeberg P, Borg S. Clinical conditions in alcoholics during long-term abstinence: a descriptive, longitudinal treatment study. Alcohol 1985;2:551-553. [PubMed: 4026978]

O'Dell LE, Roberts AJ, Smith RT, Koob GF. Enhanced alcohol self-administration after intermittent versus continuous alcohol vapor exposure. Alcohol Clin Exp Res 2004;28:1676-1682. [PubMed: 15547454]

Overstreet DH, Knapp DJ, Breese GR. Accentuated decrease in social interaction in rats subjected to multiple alcohol withdrawals. Alcohol Clin Exp Res 2002;26:1259-1268. [PubMed: 12198403]

Overstreet DH, Knapp DJ, Breese GR. Restraint stress modifies the alcohol deprivation effect and alcohol withdrawal-induced anxiety in P rats. Alcohol Clin Exp Res 2003a;27:98A.

Overstreet DH, Knapp DJ, Breese GR. Modulation of anxiety-like behavior in alcohol withdrawn rats by CRF and CRF-1 receptors. Pharmacol Biochem Behav 2004;77:405-413. [PubMed: 14751471]

Overstreet DH, Knapp DJ, Moy SS, Breese GR. A 5-HT 1 A agonist and a 5-HT $2 \mathrm{C}$ antagonist reduce social interaction deficit induced by multiple ethanol withdrawals in rats. Psychopharmacology 2003b; 167:344-352. [PubMed: 12677355]

Parsons OA, Schaeffer KW, Glenn SW. Does neuropsychological test performance predict resumption of drinking in posttreatment alcoholics? Addict Behav 1990;15:297-307. [PubMed: 2378290]

Pettinati HM, Volpicelli JR, Kranzler HR, Luck G, Rukstalis MR, Cnaan A. Sertraline treatment for alcohol dependence: interactive effects of medication and alcoholic subtype. Alcohol Clin Exp Res 2000;24:1041-1049. [PubMed: 10924008]

Pohorecky LA. Stress and alcohol interaction: an update of human research. Alcohol Clin Exp Res 1991;15:438-459. [PubMed: 1898494]

Poulos CX, Parker JL, Le AD. Dexfenfluramine and 8-OH-DPAT modulate impulsivity in a delay-ofreward paradigm: implications for a correspondence with alcohol consumption. Behav Pharmacol 1996;7:395-399. [PubMed: 11224433]

Rasmussen DD, Mitton DR, Green J, Puchalski S. Chronic daily ethanol and withdrawal: 2. Behavioral changes during prolonged abstinence. Alcohol Clin Exp Res 2001;25:999-1005. [PubMed: 11505024]

Rassnick S, Heinrichs SC, Britton KT, Koob GF. Microinjection of a corticotropin-releasing factor antagonist into the central nucleus of the amygdala reverses anxiogenic-like effects of ethanol withdrawal. Brain Res 1993;605:25-32. [PubMed: 8467387]

Richter RM, Weiss F. In vivo CRF release in rat amygdala is increased during cocaine withdrawal in self-administering rats. Synapse 1999;32:254-261. [PubMed: 10332801]

Roberts AJ, Cole M, Koob GF. Intra-amygdala muscimol decreases operant ethanol self-administration in dependent rats. Alcohol Clin Exp Res 1996;20:1289-1298. [PubMed: 8904984]

Roberts AJ, Gold LH, Polis I, McDonald JS, Filliol D, Kieffer BL, Koob GF. Increased ethanol selfadministration in delta opioid receptor knockout mice. Alcohol Clin Exp Res 2001;25:1249-1256. [PubMed: 11584142]

Roberts AJ, Heyser CJ, Cole M, Griffin P, Koob GF. Excessive ethanol drinking following a history of dependence: animal model of allostasis. Neuropsychopharmacology 2000a;22:581-594. [PubMed: 10788758]

Roberts AJ, McDonald JS, Heyser CJ, Kieffer BL, Matthes HWD, Koob GF, Gold LH. Mu opioid receptor knockout mice do not self-administer alcohol. J Pharmacol Exp Ther 2000b;293:1002-1008. [PubMed: 10869404]

Rodd-Henricks ZA, McKinzie DL, Murphy JM, McBride WJ, Lumeng L, Li TK. The expression of an alcohol deprivation effect in the high-alcohol-drinking replicate rat lines is dependent on repeated deprivations. Alcohol Clin Exp Res 2000a;24:747-753. [PubMed: 10888060] 
Rodd-Henricks ZA, McKinzie DL, Shaikh SR, Murphy JM, McBride WJ, Lumeng L, Li T-K. Alcohol deprivation effect is prolonged in the alcohol-preferring $(\mathrm{P})$ rat after repeated deprivations. Alcohol Clin Exp Res 2000b;24:8-16. [PubMed: 10656186]

Roelofs SM. Hyperventilation, anxiety, craving for alcohol: a subacute alcohol withdrawal syndrome. Alcohol 1985;2:501-505. [PubMed: 4026971]

Sapolsky RM. Stress and plasticity in the limbic system. Neurochem Res 2003;28:1735-1742. [PubMed: 14584827]

Shalev U, Highfield D, Yap J, Shaham Y. Stress and relapse to drug seeking in rats: studies on the generality of the effect. Psychopharmacology 2000;150:337-346. [PubMed: 10923762]

Sinha R. How does stress increase risk of drug abuse and relapse? Psychopharmacology 2001;158:343359. [PubMed: 11797055]

Sinha R, Catapano D, O'Malley S. Stress-induced craving and stress response in cocaine dependent individuals. Psychopharmacology 1999;142:343-351. [PubMed: 10229058]

Sinha R, Fuse T, Aubin L, O'Malley S. Psychological stress, drug-related cues and cocaine craving. Psychopharmacology 2000;152:140-148. [PubMed: 11057517]

Sinha R, Talih M, Malison R, Anderson GA, Cooney N, Kreek MJ. Hypothalamic-pituitary-adrenal axis and sympatho-adreno-medullary responses during stress-induced and drug cue-induced cocaine craving states. Psychopharmacology 2003;170:62-72. [PubMed: 12845411]

Sloan TB, Roache JD, Johnson BA. The role of anxiety in predicting drinking behaviour. Alcohol Alcohol 2003;38:360-363. [PubMed: 12814905]

Spanagel R, Hölter SM. Long-term alcohol self-administration with repeated alcohol deprivation phases: an animal model of alcoholism? Alcohol Alcohol 1999;34:231-243. [PubMed: 10344783]

Timpl P, Spanagel R, Sillaber I, Kresse A, Reul JM, Stalla GK, Blanquet V, Steckler T, Holsboer F, Wurst W. Impaired stress response and reduced anxiety in mice lacking a functional corticotropinreleasing hormone receptor. Nat Genet 1998;19:162-166. [PubMed: 9620773]

Valdez GR, Roberts AJ, Chan K, Davis H, Brennan M, Zorrilla EP, Koob GF. Increased ethanol selfadministration and anxiety-like behavior during acute ethanol withdrawal and protracted abstinence: regulation by corticotropin-releasing factor. Alcohol Clin Exp Res 2002;26:1494-1501. [PubMed: 12394282]

Valdez GR, Zorrilla EP, Roberts AJ, Koob GF. Antagonism of corticotropin-releasing factor attenuates the enhanced responsiveness to stress observed during protracted ethanol abstinence. Alcohol 2003;29:55-60. [PubMed: 12782246]

Weiss F, Porrino LJ. Behavioral neurobiology of alcohol addiction: recent advances and challenges. J Neurosci 2002;22:3332-3337. [PubMed: 11978808]

Willinger U, Lenzinger E, Hornik K, Fischer G, Schönbeck G, Aschauer HN, Meszaros K. Anxiety as a predictor of relapse in detoxified alcohol-dependent patients. Alcohol Alcohol 2002;37:609-612. [PubMed: 12414556]

Young RM, Oei TP, Knight RG. The tension reduction hypothesis revisited: an alcohol expectancy perspective. Br J Addict 1990;85:31-40. [PubMed: 2178706] 


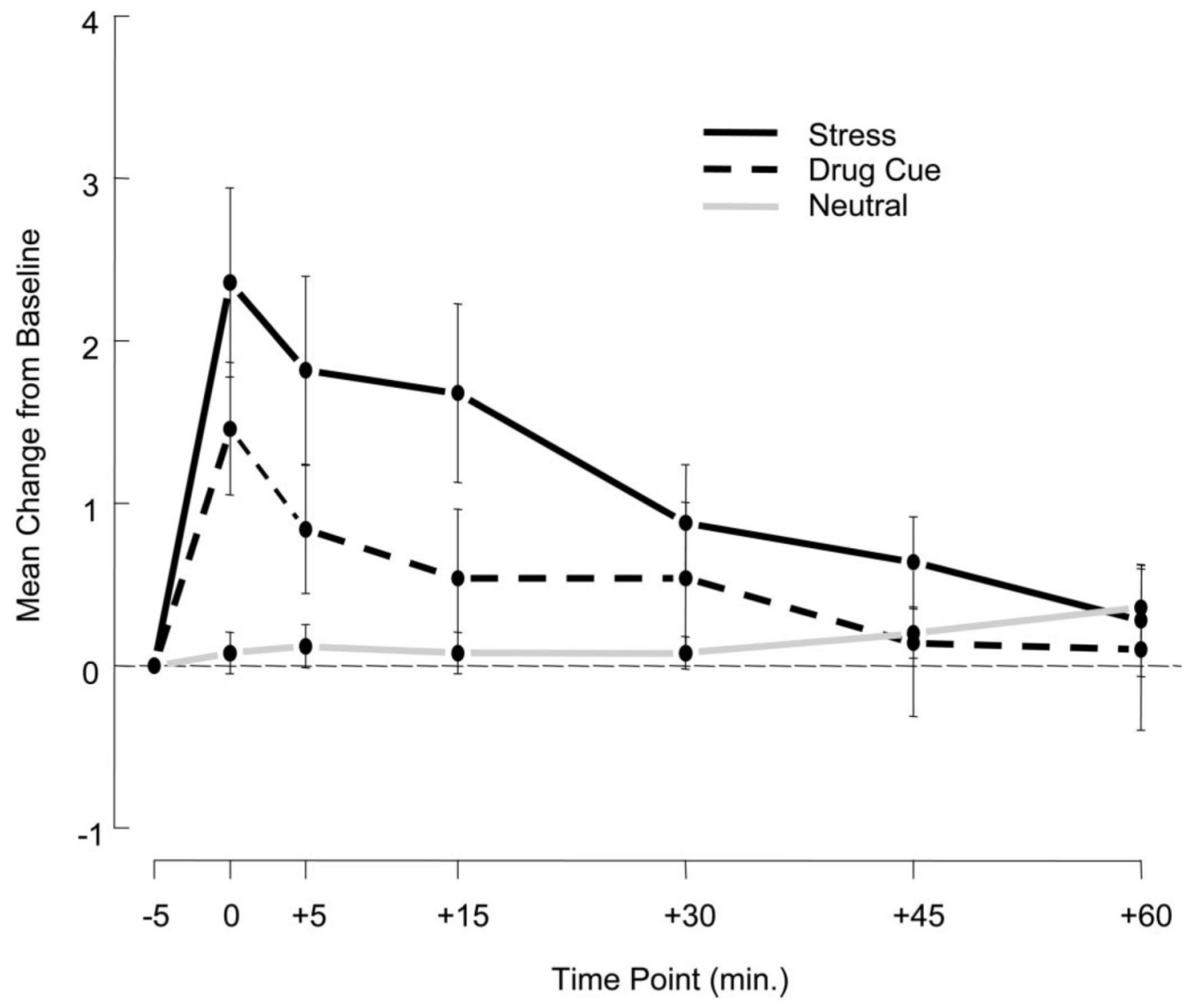

Fig. 1.

Alcohol craving after stress and other imagery conditions. Shown is the mean change from baseline in alcohol craving after exposure to stress (S), drug/alcohol cue (D), and neutral relaxing $(\mathrm{N})$ imagery conditions on separate days in 25 cocaine-dependent alcoholics [condition main effect: $F(2,408)=18.1, p<0.0001 ; \mathrm{S}>\mathrm{DC}>\mathrm{N}$ ] immediately after imagery exposure ( 0 time point) and up to $60 \mathrm{~min}$ after imagery exposure [time point main effect: $F(5$, $408)=4.5, p<0.0005]$. 


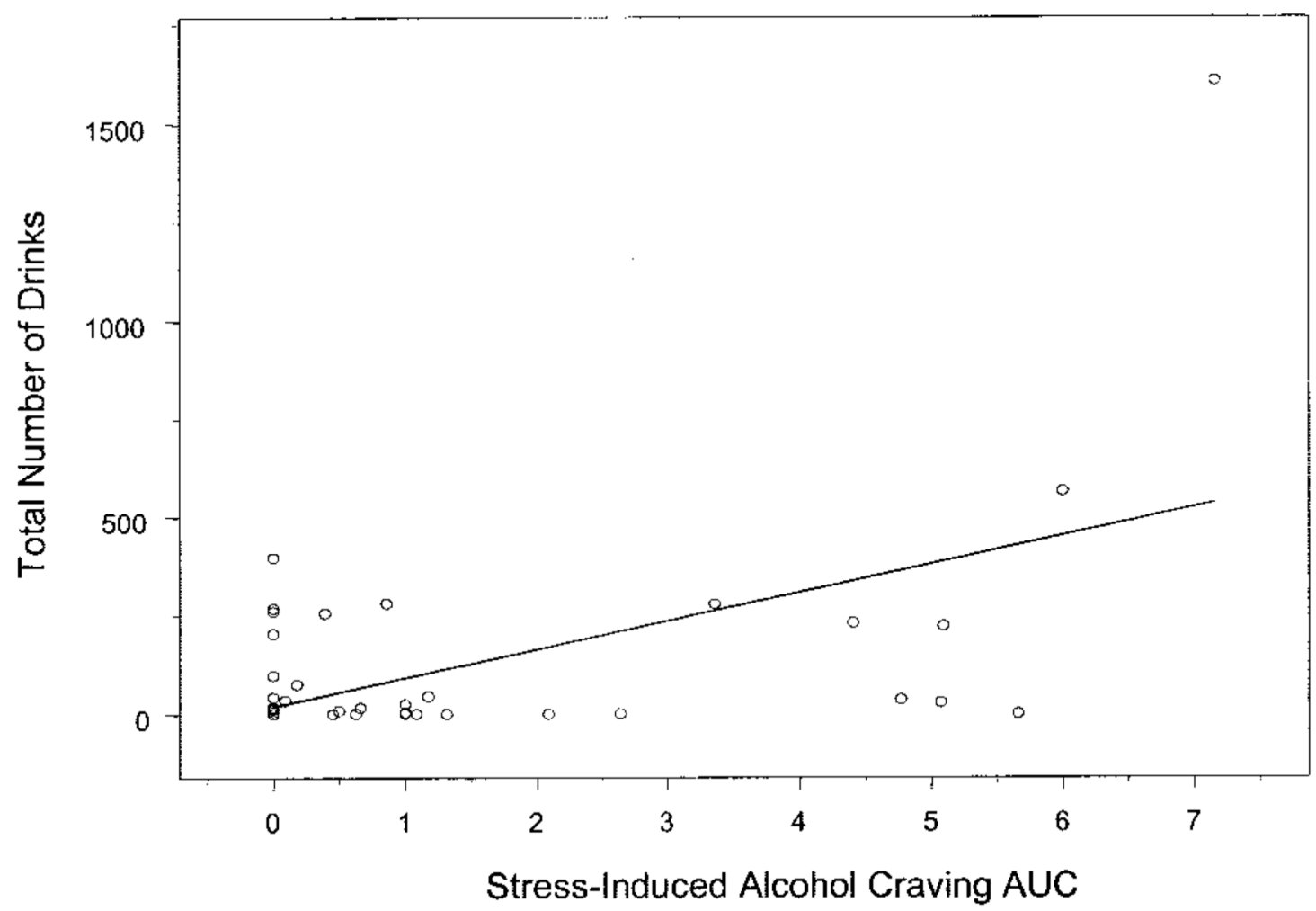

Fig. 2.

Relation of stress-induced craving and drinks consumed. Scatterplot for stress-induced alcohol craving area under the curve (AUC) response during the inpatient laboratory session and total number of drinks consumed in the 90 days after discharge from inpatient drug treatment $\left(R^{2}\right.$ $=0.30, r=0.55, p<0.0001)$ in 49 cocaine- and alcohol-abusing patients. Alcohol craving in response to drug/alcohol cues or to neutral relaxing imagery exposure was not associated with drinking after discharge. 


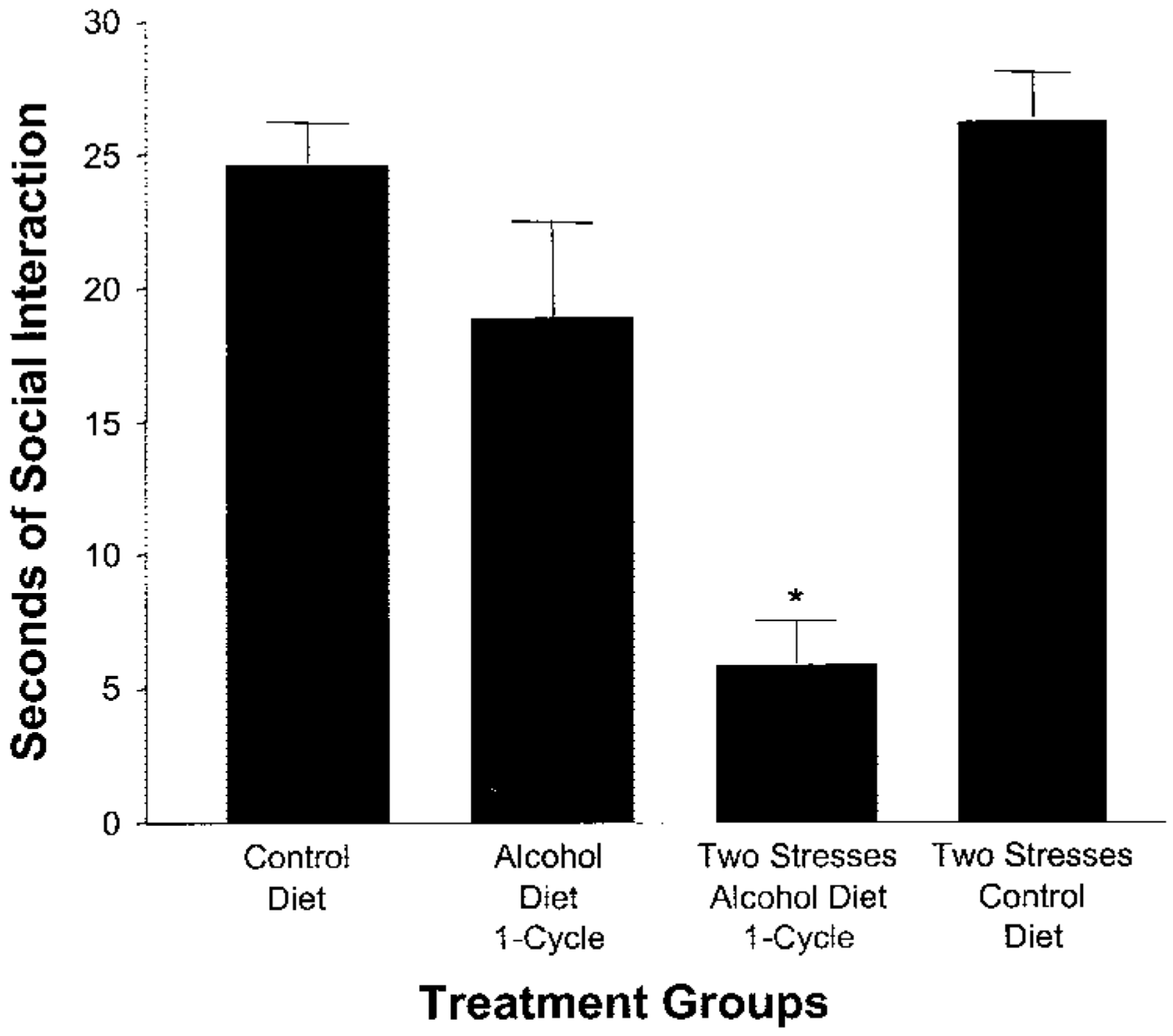

Fig. 3.

Stress sensitization of the withdrawal-induced reduction in social interaction. Rats were exposed to either control diet, a single cycle of 5 days of $7 \%$ alcohol diet and withdrawal (alcohol diet-1 cycle), stress application at 6 and 11 days while on liquid diet followed by a 5day cycle of $7 \%$ alcohol liquid diet (two stresses-alcohol diet-1 cycle), or two stresses followed by exposure to control diet (two stresses-control diet). Social interaction testing was performed between 5 and $6 \mathrm{hr}$ either after the final alcohol diet or when the control diet treatment was terminated (see Breese et al., 2004a). $* p<0.01$ vs. other groups. 